\title{
Stage I Kidney Wilms Tumor
}

National Cancer Institute

\section{Source}

National Cancer Institute. Stage I Kidney Wilms Tumor. NCI Thesaurus. Code C7840.

Wilms tumor that is found in one kidney and can be completely removed with surgery.

(National Wilms Tumor Study Group Staging System) 